Int. J. Electrochem. Sci., 13 (2018) $196-208$

\title{
Synthesis and Characterization of Poly(o-ethoxyaniline)/Nano Silica Composite and Study of its Anticorrosion Performance
}

\author{
Hongli Cheng ${ }^{1, *}$, Chuanbo $\mathrm{Hu}^{2}$, Xianglan Wang ${ }^{1}$, Ziqiang $\mathrm{He}^{1}$ \\ ${ }^{1}$ Department of Chemical and Environmental Engineering, Wuhan Institute of Bioengineering, Wuhan \\ 430415, China \\ ${ }^{2}$ School of Metallurgy, Northeastern University, Shenyang 110819, China \\ *E-mail: $\underline{\text { chl20111027@ 126.com }}$
}

doi: $10.20964 / 2018.01 .12$

Received: 12 September 2017 / Accepted: 13 October 2017 / Online Published: 1 December 2017

\begin{abstract}
The poly(o-ethoxyaniline)/nano silica $\left(\mathrm{POEA} / \mathrm{SiO}_{2}\right)$ composite material was synthesized by in-situ polymerization method. The structure, composition and morphology were characterized by Fourier transform infrared spectroscopy (FT-IR), UV-visible adsorption spectroscopy (UV-vis), X-ray diffraction patterns (XRD) and field emission scanning electron microscopy (SEM). The thermal stability was studied by Thermogravimetric analysis (TGA). The electrochemical behaviors were performed by cyclic voltammetry (CV) technique. Epoxy coatings containing $\mathrm{SiO}_{2}$ nanoparticles, POEA and POEA/SiO 2 powders were prepared on the surface of the treated carbon steel. The surface morphology of the coatings was observed by FESEM, the electrochemical corrosion behavior was studied by Tafel polarization curve and electrochemical impedance spectroscopy (EIS) in 3.5\% $\mathrm{NaCl}$ solution. The results show that the POEA/SiO $\mathrm{S}_{2}$ containing coating exhibit a lower corrosion rate of $0.02 \mathrm{~mm} /$ year and the corrosion protection efficiency is as high as $98.9 \%$. The EIS measurement was also demonstrate that the addition of $\mathrm{POEA} / \mathrm{SiO}_{2}$ could improve the anticorrosion performance of epoxy coating significantly than that of POEA and $\mathrm{SiO}_{2}$ nanoparticles.
\end{abstract}

Keywords: POEA; $\mathrm{SiO}_{2}$ nanoparticles; Electrochemical; Anticorrosion performance

\section{FULL TEXT}

(C) 2018 The Authors. Published by ESG (www.electrochemsci.org). This article is an open access article distributed under the terms and conditions of the Creative Commons Attribution license (http://creativecommons.org/licenses/by/4.0/). 